\title{
A Comparative Study of Corrosive-Erosive Effects at AISI D3 Steel, 304 Stainless Steel and CrN/AIN Material
}

\author{
J.C. Caicedo ${ }^{*}, 1,2$, G. Cabrera ${ }^{1}$, H.H. Caicedo ${ }^{3,4}$ and W. Aperador ${ }^{5}$ \\ ${ }^{I}$ School of Materials, Universidad del Valle, Colombia \\ ${ }^{2}$ Advanced Materials for Micro and NanoTechnology Research Group, Universidad Autónoma de Occidente, Cali, \\ Colombia \\ ${ }^{3}$ Department of Bioengineering, ${ }^{4}$ Department of Anatomy and Cell Biology, University of Illinois at Chicago, IL 60612, \\ USA \\ ${ }^{5}$ Ingenieria Mecatrónica, Universidad Militar Nueva Granada, Bogotá, Colombia
}

\begin{abstract}
Corrosive-erosive effect on AISI D3 steel, 304 stainless steel and $\mathrm{CrN} / \mathrm{AlN}$ coating in aqueous $\mathrm{NaCl}$ slurries was studied. CrN/AIN multilayer films with a thickness of $3 \mu \mathrm{m}$ and bilayer period of $\Lambda=60 \mathrm{~nm}$ (50 bilayers) were obtained by using the physical vapor deposition (PVD) technique (magnetron sputtering). The corrosion-erosion experiments were performed in a test machine in which the impingement velocity, impact angle, concentration of solids and $\mathrm{pH}$ of the solution were controlled. Polarization curves were simultaneously obtained to correlate the electrochemical effects to the erosive wear mechanisms. The slurry used consists of silica particles suspended in a mixture of acid solution and $3.5 \% \mathrm{NaCl}$, with a $\mathrm{pH}$ value of 5.6. Electrochemical results showed the best corrosion resistance for 304 stainless steels. Additionally, the surface analysis by SEM micrograph revealed formation of cracks in CrN/AlN multilayers coating and plastic deformation in both steel substrates (AISI D3 steel, 304 stainless steel), especially when the mean impact angle is a critical value of $90^{\circ}$. Measurements of critical and passive current densities showed that the behavior of coated materials differed depending on the substrate that is used. Nonetheless, in a general way, by increasing the impact angle and by changing its incidence from normal to grazing, it led to a resistance to corrosion-erosion processes.
\end{abstract}

Keywords: Corrosion-erosion, multilayer coating, electrochemical tests, surface analysis.

\section{INTRODUCTION}

The mechanical, tribological and resistance to corrosion properties of materials, as well as the synergy between them, play a critical role in a myriad of scientific and industrial applications. Strikingly, corrosion-erosion processes are vastly investigated due to the devastating effects that are observed in materials such as metals, ceramics or polymers. In the case of metals, corrosion-erosion processes affect engineered structures such as pipes, diaphragms, offshore to energy conversion, food processing systems and many others for chemical, petrochemical and marine applications. When corrosion and erosion act together the degradation mechanisms are complex and generally the measured mass losses are higher than the sum of separated material losses due to both corrosion and erosion $[1,2]$. Impact velocity and impact angle have been recognized as two parameters that noticeably influence the wear rates and surface degradation in tribosystems that suffer erosion and corrosion-erosion. Burstein and Sasaki studied the effect of the impact angle on corrosion-erosion of AISI 304L stainless steel and found that the maximum values of both erosion and corrosion-erosion rates in chloride solution occurred at oblique angles

*Address correspondence to this author at the School of Materials, Universidad del Valle, Colombia;

Tel.: 57+2+339 46 10, Ext. 42; Fax: 57+2+339 46, +1.312.9960402; E-mails: jcaicedoangulo@gmail.com, caicedo.hugo@gmail.com between $40^{\circ}$ and $50^{\circ}$, and that the synergism was positive in all conditions and greater for lower angles [3]. Other authors have also reported positive corrosion-erosion synergism in slurry wear tests of stainless steels [4-6]. Positive synergism arises from the notion that when the metal is submitted to hard particle impact, each erosive event causes rupture or removal of the protective oxide film from the surface, leaving the metallic substrate exposed to the solution. Moreover, in microstructures where hard and disperse second phases such as chromium carbides are present, uniform corrosion of metallic matrix can accelerate the hard particle release from the surface and increase the total mass loss. Usually, in the stainless steels case, the control of little changes in microstructure or in the environmental conditions is crucial, since the synergistic effects are sensitive to microscopic features such as second phase precipitates, grain boundaries and surface texture of the components [6-10]. On the other hand, development of hard corrosion resistant coatings has always been a limited solution to minimize the erosive and corrosive combined attack. In that sense, physical vapor deposition (PVD) deposition technology has progressed in recent years resulting in multilayer coatings of various combinations of metals, their oxides and nitrides possessing high tribological properties and corrosion resistance $[11,12]$, e.g. steel substrates coated with multilayer system have showed an increase of corrosive protection as function the bilayer period $(\Lambda)$ [CrN/AIN]n [7]. Also the corrosive-erosive effect on steel coated with 
[TiN/AITiN]n has been study and reported by W. Aperador et al. [8]. In those studies, they found that coated substrates showed a better erosion resistance for impact velocity lower than $12 \mathrm{~m} / \mathrm{s}$. After that, the coating was removed from the substrate surface by perforation and spalling $[8,9]$. The aim of this work is to study the effect of impact angle on the corrosion-erosion resistance of commercial AISI D3 steel uncoated, AISI 304 stainless steel uncoated and AISI D3 steel coated with CrN/AIN multilayer system under corrosive slurry containing chloride ions $\left(\mathrm{Cl}^{-}\right)$and hard erosive particles. Additionally, this work compared the corrosion-erosion behavior presented by the AISI 304 stainless steel AISI D3 steel coated with CrN/AIN multilayer system and AISI D3 steel uncoated.

\section{EXPERIMENTAL DETAILS}

\subsection{Materials}

AISI D3 steels and austenitic AISI 304 stainless steel cylinders with $10 \mathrm{~mm}$ in diameter and $7 \mathrm{~mm}$ in height were used. The chemical compositions of the steels are shown in Table 1. The AISI D3 samples were austenized at $1250^{\circ} \mathrm{C}$ for $1 \mathrm{~h}$, oil-quenched and tempered at $970{ }^{\circ} \mathrm{C}$ for another hour. The microstructure obtained after this procedure was composed of martensite laths, retained austenite and dispersed carbides. On the other hand, the AISI 304 samples had a microstructure composed of austenite grains and some deformation bands formed as a consequence of cold working.

Table 1. Chemical Composition and Mechanical Properties (Hardness) of the Steels Used in this Investigation (wt.\%)

\begin{tabular}{|c|c|c|}
\hline Material & $\begin{array}{c}\text { AISI D3 } \\
\text { 30 (HRC) }\end{array}$ & $\begin{array}{c}\text { AISI 304 } \\
\mathbf{3 0} \text { (HRC) }\end{array}$ \\
\hline \hline $\mathrm{Cr}$ & 12.0 & 18.4 \\
\hline $\mathrm{C}$ & 2.10 & 0.08 \\
\hline $\mathrm{Ni}$ & - & 8.2 \\
\hline $\mathrm{Mn}$ & 0.30 & 0.9 \\
\hline $\mathrm{Si}$ & 0.30 & 0.66 \\
\hline
\end{tabular}

\subsection{Multilayers Coating Deposition}

CrN/AIN multilayers were deposited onto silicon (100) and AISI D3 steel substrates by using a multi-target r.f. magnetron sputtering system, with an r.f. source (13.56 $\mathrm{MHz})$ for the applied bias voltage $(-50 \mathrm{~V})$ on the substrate, and metallic $\mathrm{Cr}$ and $\mathrm{Al}$ targets with $99.9 \%$ purity. The coatings were deposited on $\mathrm{Si}$ substrates due to the preferential orientation which facilitates the analysis of Xray diffraction patterns, and has little influence on IR spectra. A $350 \mathrm{~W}$ magnetron power was applied to the $\mathrm{Cr}$ target, while a power of $400 \mathrm{~W}$ was applied to the $\mathrm{Al}$ target. The deposition chamber was initially pumped down to less than $5 \times 10^{-6}$ mbar, using a gas mixture of $\mathrm{Ar}(92 \%)+$ $\mathrm{N}_{2}(8 \%)$. The substrate temperature was around $250{ }^{\circ} \mathrm{C}$ and a substrate to target distance of $7 \mathrm{~cm}$ was maintained for all coatings. For multilayer depositions, the aluminum and chromium targets were covered periodically with a steel shutter. Before the depositions, the targets and substrates were sputter-cleaned over $20 \mathrm{~min}$; during the depositions, the pressure of the chamber was kept at $2 \times 10^{-3}$ mbar. The thickness ratios of CrN/AlN multilayers systems were obtained by means of a Dektak 3030 profilometer. The crystal structure of the coating was determined by using a $D 8$ Advance Bruker X-ray diffractometer with $\mathrm{Cu}-\mathrm{K} \alpha$ $(\lambda=1.5405 \AA)$ radiation. Chemical composition of the coatings was determined by energy dispersive X-ray spectroscopy (EDX) using a Philips XL3OFEG. The structural assembly of the multilayers was analyzed by scanning electron microscopy (SEM) (Philips XL3OFEG) equipped with a light optical magnification range: 52524.000X.

For each sample it was used an average of three samples corresponding to six different tests associate to three materials.

\subsection{Surface Properties Tests}

For the analysis of the erosive-corrosive effect a system built for the evaluation of chemical attack in metallic materials was used. Fig. (1) shows the erosive-corrosive testing system consisting of a tribometer with a glass container for erosive-corrosive storage, one reference and one counter electrode, an acrylic cover that is available in the sample holder and electrodes, a impeller of High Ultra Molecular Weight Polyethylene (HUMWPE) which rests on the teflon shaft that is attached to the main motor shaft that provides fluid motion. The lid of the container allows locating two different samples exposed under angles for corrosive fluid action $\left(30^{\circ}\right.$ and $\left.90^{\circ}\right)$. In this custom-made system, the fluid movement is caused by a shaft driver of the motor. The tangential speed applied to the fluid with erosive particles was fixed to $11.12 \mathrm{~m} / \mathrm{s}$, which takes into account that the impeller radius is $0.055 \mathrm{~m}$ and that the motor speed was fixed to $500 \mathrm{rpm}$. Due to that the particle speed was determined as function of the fluid movement is caused by a shaft driver of the motor, particle density and viscosity of the fluid. The electrochemical study was carried out with a Gamry unit; model PCI4 with DC signals, which generate Tafel polarization curves. These curves were realized at room temperature using a cell that supported one working electrode within an exposed area of $1 \mathrm{~cm}^{2}$, a reference electrode $(\mathrm{Ag} / \mathrm{AgCl})$ and a graphite counter electrode under a $3.5 \% \mathrm{NaCl}$ solution, into distilled water. This solution was chosen because it is used to study steel as it facilitates the observation at a defined anodic region and chloride addition, making sure an effective corrosive and chemical attack. While the resting potential was measured during $30 \mathrm{~min}$ intervals, the Tafel curves were taken as a function of time, i.e. between $15 \mathrm{~min}$ and $250 \mathrm{~min}$, where the impact angles on surface samples on each test were $30^{\circ}$ and $90^{\circ}$, respectively. This time was necessary for anodic and cathodic sweep potential. Tafel polarization curves were obtained at a sweep speed of $0.5 \mathrm{mV} / \mathrm{s}$ in voltage range from $-0.2 \mathrm{~V}$ to $0.8 \mathrm{~V}$ with an exposed area of $1 \mathrm{~cm}^{2}[8,13]$. In this study, a silica solution $\left(\mathrm{SiO}_{2}\right)$ with particle sizes between $2.10 \mathrm{~mm}$ and $3.00 \mathrm{~mm}$ was used as an abrasive agent in the erosivecorrosive test with a linear velocity of $3.61 \mathrm{~m} / \mathrm{s}$. 


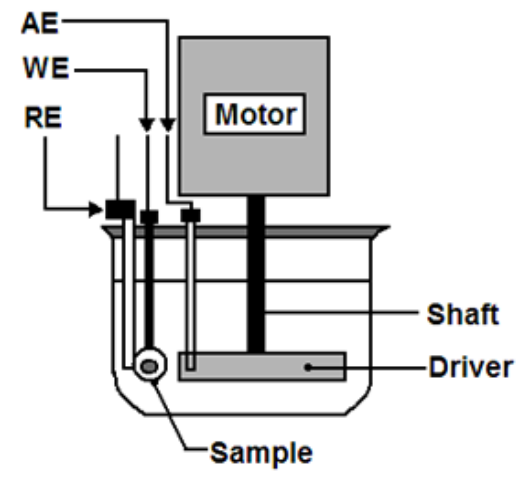

Fig. (1). Schematic of the custom-made system used in the corrosion-erosion wear test. Auxiliary electrode (AE), working electrode (WE), reference electrode (RE) [8].

The surface examination and microstructure analysis was used for analyzing the process of surface corrosion, the superficial morphology was characterized by using a HighResolution Scanning Electron Microscope (SEM) (Philips XL30FEG).

\section{RESULTS AND DISCUSSION}

\subsection{Characterization of Multilayer Coatings}

From our previous work [7], Fig. (2) shows a typical XRD diffraction pattern of CrN/AlN deposited onto a (100) silicon substrate with $\Lambda=300 \mathrm{~nm}$ and $\mathrm{n}=10 . \mathrm{CrN}$ and AlN layers within the multilayer system showed to be polycrystalline exhibiting diffraction peaks with a preferential orientation (100) corresponding to $w$-AlN phase located at $33.48^{\circ}$. Other peaks, attributed to AlN structure, were found at $72.40^{\circ}, 77.50^{\circ}$ and $82.54^{\circ}$, which corresponds to planes (201), (004) and (202), respectively, these were. The diffraction peaks at $37.88^{\circ}, 44.12^{\circ}$ and $64.32^{\circ}$ corresponding to planes (111), (200) and (220), respectively, are for $\mathrm{CrN}$ cubic structure. The diffraction peaks at $40.84^{\circ}$ and $55.54^{\circ}$ corresponding to planes (002) and (112), are associated to $\mathrm{Cr}_{2} \mathrm{~N}$ hexagonal structure [14-16]. These preferential orientations are in agreement with JCPDF 00025-1133 and JCPDF 00-011-0065 from AlN and CrN ICCD cards, respectively. Additionally, Table 2 shows the energydispersive X-ray spectroscopy (EDX) values of AIN and $\mathrm{CrN}$ single layers, respectively, deposited with an r.f. negative bias voltage of $-50 \mathrm{~V}$. All samples were observed via SEM and chemical analyses were done with an amplification of $20000 \mathrm{X}$.

SEM examination mapping of the multilayer assembly of the coated specimens (see Fig. 3) revealed the formation of the CrN/AIN multilayer system with $\Lambda=60 \mathrm{~nm} \mathrm{(50}$ bilayers). The darkest contrast of $\mathrm{CrN}$ layers with respect to those of AIN allowed a clear determination of the layer structures. These $\mathrm{CrN} / \mathrm{AlN}$ multilayer coatings presented a well-defined and uniform periodicity through of the thickness. All the multilayer stacks were resolved by SEM and confirmed quite precisely by the previously designed nominal values of the multilayer thickness $(3 \mu \mathrm{m})$. In this way, it was possible to show that AIN layers are marginally thicker than those of CrN (inset Fig. 3); therefore, by SEM analysis, it was also confirmed that for each multilayer there is a different deviation of 0.2 layer thickness ratio.

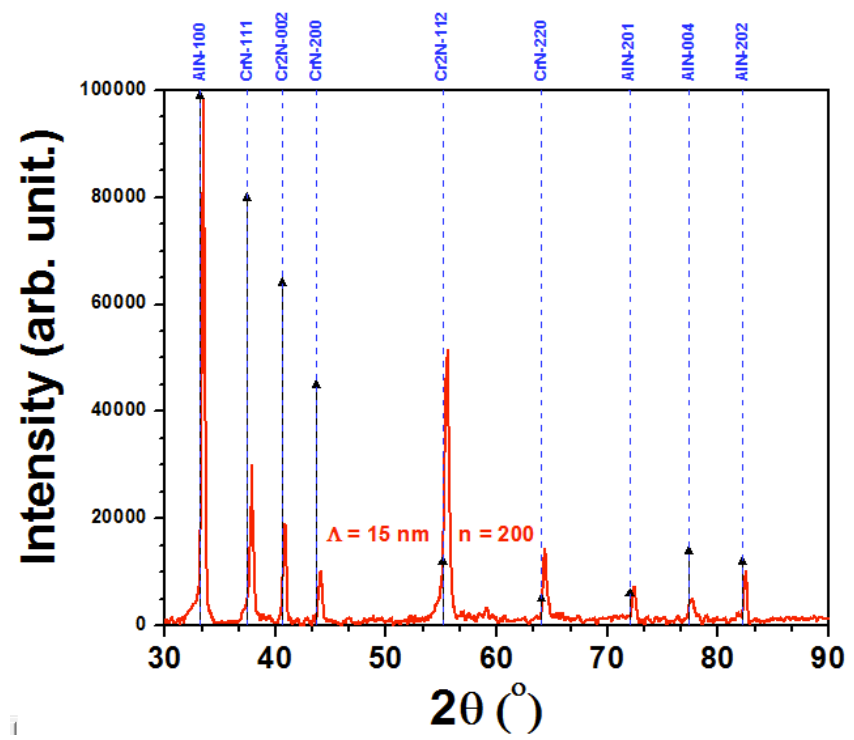

Fig. (2). XRD pattern of the CrN/AlN multilayer coatings deposited with $\mathrm{n}=200(\Lambda=15 \mathrm{~nm})$ showing the preferential orientation $\operatorname{AlN}(110)$ and $\mathrm{Cr}_{2} \mathrm{~N}(112)$.

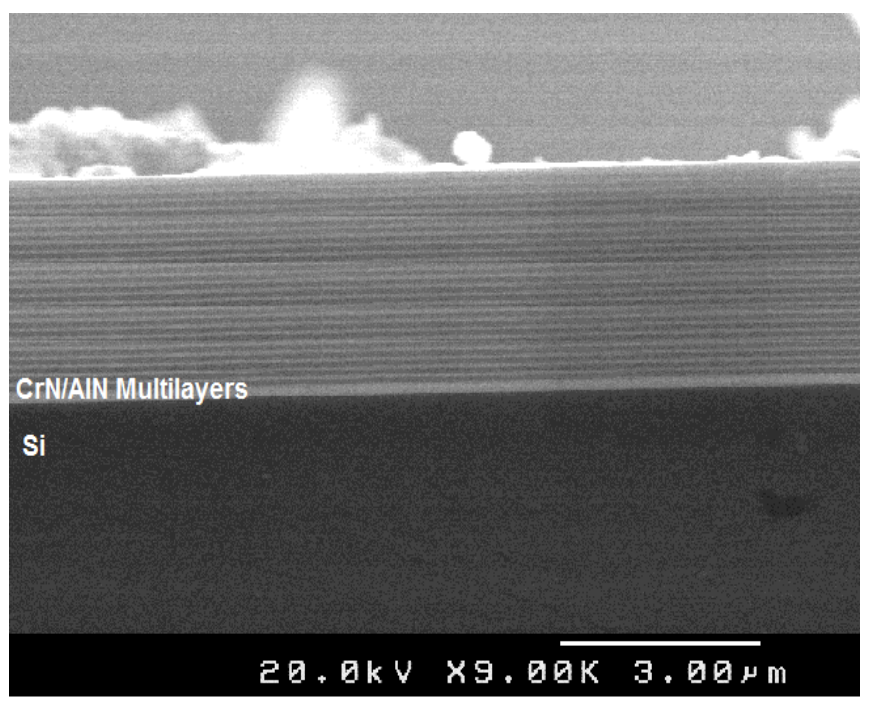

Fig. (3). CrN/AlN multilayer coatings analyzed by SEM image, showing the modulation structure.

Table 2. Stoichiometric Relationship Determined by EDX, Lattice Parameter of Al-N, Cr-N and Hardness by Nanoindentation of Multilayer Coatings [17]

\begin{tabular}{|c|c|c|c|c|}
\hline \multicolumn{2}{|c|}{ Composition from Single Layers } & \multicolumn{2}{|c|}{ Lattice Parameters from Single Layers } & \multirow{2}{*}{ Hardness [CrN/AIN] ${ }_{200}$ (Nanoindentation) } \\
\hline \hline \multirow{2}{*}{$\mathrm{Al}_{68} \mathrm{~N}_{32}$} & \multirow{2}{*}{$\mathrm{Cr}_{65} \mathrm{~N}_{35}$} & 0.303 and 0.499 & Cubic FCC Cr $\mathrm{N}_{\mathrm{y}}(111) \mathrm{a}_{0}(\mathrm{~nm})$ & \multirow{2}{*}{$28(\mathrm{GPa})$} \\
\cline { 3 - 4 } & & 0.303 and 0.499 & 0.410 & \\
\hline
\end{tabular}




\subsection{Erosion Analysis Without Corrosive Effect}

The wear indicators, such as mass loss, related to erosive mechanisms without corrosive effect as a function of exposure time for differents materials (AISI D3 steel, 304 stainless steel and CrN/AIN multilayers) under two impact angles $\left(30^{\circ}\right.$ and $\left.90^{\circ}\right)$ are showed in Fig. (4a, b), respectively. In this work, it was noted that the decrease in wear rate is related to the nature of the material, since the wear generated on the different samples is the result of successive impacts of abrasive particles on the surface of the material, with an average linear velocity of $3.61 \mathrm{~m} / \mathrm{s}$. In order to make a comparative analysis between the different materials according to the test conditions, it is necessary different dynamic curves of wear produced in an erosive liquid medium (made with hard silica particles and distillated water). The results in Fig. (4) clearly show the severity of the wear with respect to variation of the impact angle of attack in all the materials that were tested, where the condition of normal angle $\left(90^{\circ}\right)$ is further loss of material thickness compared to the grazing angle $\left(30^{\circ}\right)$. Such behavior can be seen associated with the removal of material forms in each situation. In the grazing case, the incidence angle is an expected phenomenon of micro-cutting and micro-plowing; while in the normal case, wear angle is governed by surface fatigue phenomena. This leads us to conclude that the dominant micro-mechanisms of wear in each case operate differently.

Erosion tests in AISI D3 steel (Fig. 4a, b), show that the mass loss is significant in the first hour under constant rotation of the material against the liquid with erosive particles, after that period of time the mass loss tends to stabilize. It is also noted that wear is potentiated by both impact angles, i.e. grazing $\left(30^{\circ}\right)$ and normal $\left(90^{\circ}\right)$ being the normal angle the parameter that generates greater mass loss. The evidence of erosion for AISI 304 stainless steel (Fig. 4a, b) under impact an angle of $90^{\circ}$ shows the highest increase in mass loss for this angle; noticeable enough, in this case the values tend to stabilize after the first hour of the test. Comparing the AISI D3 steel and AISI 304 stainless steel behavior is noted that for two impact angles $\left(30^{\circ}\right.$ and $\left.90^{\circ}\right)$, it

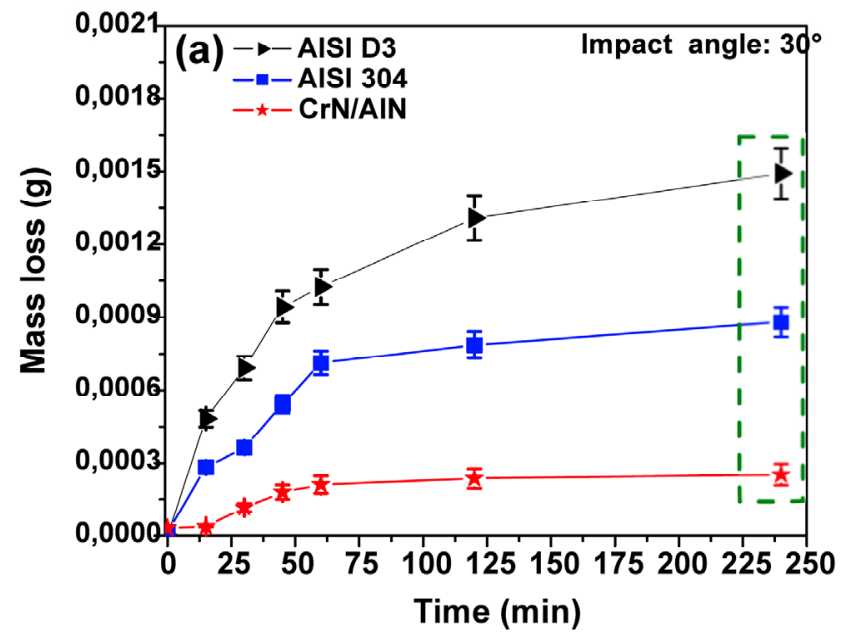

is clear the greater mass loss for the steel AISI D3. This indicates a greater resistance to both wear and surface fatigue of the stainless steel, this being possibly attributed to the oxide layer. Hence, when the effect of $30^{\circ}$ angle attack, on samples within water flow with silica particles, it is compared to that of $90^{\circ}$ angle attack, the samples under the $30^{\circ}$ angle attack exhibit lower mass loss in relation to the impact angle of $90^{\circ}$. On the other hands, the damping signs in the wear phenomenon for the CrN/AIN multilayer system is observed by the logarithmic trend in the curves (Fig. 4a, b), evidencing that the CrN/AlN material presents a strain hardening that moves into the coating because the interfaces between each layer can adsorb and dissipate the energy generated by the impact of the particles; thus providing, more wear-resistant surface $[17,18]$.

Comparing the mass loss of AISI D3 steel, AISI 304 stainless steel and steel coated with the CrN/AIN multilayer system (Fig. 5), is possible to observe in the first hour under wear test condition, that the AISI D3 steel present the greatest mass loss, followed by AISI 304 stainless steel and finally steel coated with CrN/AlN. This shows clearly the effect wear protective multilayer coating surface when the multilayers are deposited on steel substrate and thus, the multilayer system can be a possible candidate to mitigate the wear problems which they are subjected most industrial steels.

\subsection{Corrosion Analysis Without Erosive Effect}

Tafel polarization curves as a function of the corrosion current density for the AISI D3 steel, stainless steel AISI 304 and steel D3 coated with CrN/AlN multilayer without erosive effect for two impact angles, $30^{\circ}$ and $90^{\circ}$, are shown in Fig. (6a, b), respectively. Tafel polarization curves have been used to found anodic and cathodic slope values in each case which are necessary to calculate a correct value of the surface corrosion rate without erosive effect. In this way, Tafel polarization curves are strongly dependent on the nature of the material, indicating the influence of differences in the type and size grain, therefore, the Nickel (Ni) element with $8.2 \%$ in the AISI 304 case generate a high corrosion potential when is compared to AISI D3 steel and a hard

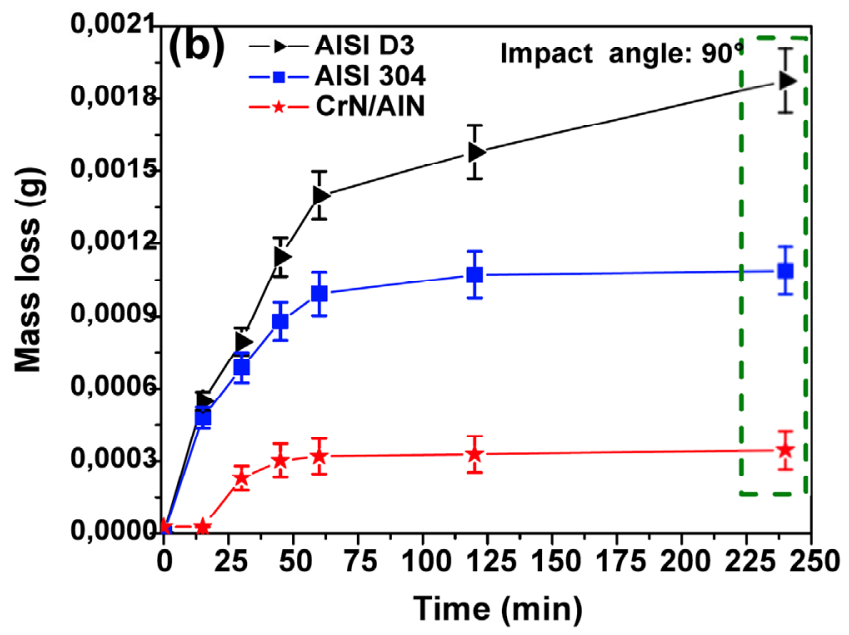

Fig. (4). Mass loss as a function of exposure time for AISI D3 steel, 304 stainless steels and CrN/AlN multilayer coatings: (a) show the impact angle corresponding to $30^{\circ}$ and (b) show the impact angle corresponding to $90^{\circ}$. The highest mass loss corresponding to the highest time is present within guides to the eyes (dotted lines). 
Table 3. Total Mass Loss by Erosive Effect as Function of Different Materials for Two Impact Angles $\left(30^{\circ}\right.$ and $\left.90^{\circ}\right)$

\begin{tabular}{|c|c|c|c|}
\hline & Steel AISI D3 & Stainless Steel 304 & CrN/AIN Multilayer \\
\hline \hline Impact angle $\left(\mathbf{3 0}^{\circ}\right)$ & $4.41 \times 10^{-3}(\mathrm{~g})$ & $2.05 \times 10^{-3}(\mathrm{~g})$ & $4.51 \times 10^{-4}(\mathrm{~g})$ \\
\hline Impact angle $\left.\mathbf{( 9 0 ^ { \circ }}\right)$ & $5.95 \times 10^{-3}(\mathrm{~g})$ & $3.48 \times 10^{-3}(\mathrm{~g})$ & $8.40 \times 10^{-4}(\mathrm{~g})$ \\
\hline
\end{tabular}

difference in the CrN/AIN coatings when is compared with AISI D3 steel due to interfaces present within multilayers [7]. From Fig. (5) it is possible to observe that the CrN/AlN multilayer system behave better than the other materials showing less current density and higher corrosion potential which remarks the protective effects of the multilayer coatings because the multilayer modulation, demand more energy from the $\mathrm{Cl}^{-}$ions, thus reducing the corrosive attack on multilayered systems [19]. So, this protective effect is characteristic of multilayer structures; as a consequence of high bilayer and interface number. The corrosive effect present in this research is in agreement with previous result presented by G. Cabrera [7].

The general trend was to reduce the corrosion rate when the nature of the material is modified, from barely being AISI D3 steel to being AISI D3 steel plus a CrN/AIN multilayer coating. This last system presents lowest corrosion rate due to the high interface number with nanometric thickness $\left(\Lambda=\mathrm{t}_{\mathrm{CrN}}+\mathrm{t}_{\mathrm{AlN}}=60 \mathrm{~nm}\right)$, as was observed on the SEM micrograph (Fig. 3). Finally, in the Table 4 it is shown the corrosion rate as a function of the differents materials (AISI D3 steel, AISI 304 stainless steel and $\mathrm{D} 3 / \mathrm{CrN} / \mathrm{AlN})$ with two different impact angles $\left(30^{\circ}\right.$ and $90^{\circ}$ ), where it is possible to observe the high corrosion rate in samples under normal angles $\left(90^{\circ}\right)$. It is seen that the $(\mathrm{Ni})$ element in the AISI 304 and nanometric layers in steel coated with CrN/AIN multilayers exhibited a dramatic decrease in corrosion rate.

Taking into account the erosion analysis without corrosive effect and the corrosion analysis without erosive effect, it is possible to conclude that corrosive failure of steel substrate uncoated (AISI D3 and AISI 304) under the action of a corrosive medium occurs at structural defects (pin holes, pores, micro-cracks, etc.), therefore, the corrosion resistance of multilayer nitride coatings (CrN/AlN) is higher than that of steel and stainless steel, which may be explained by their greater interface number and features of their microstructure, including the absence of circular crystals characteristic of single-layer coatings [20]. In this regard, in this work was observed that the corrosion potentials for steel AISI 304 and steel coated with $\mathrm{CrN} / \mathrm{AlN}$ under two impact angles $\left(30^{\circ}\right.$ and $90^{\circ}$ ) are more electropositive compared to the uncoated steel AISI D3, thus confirming the protective effects of the coatings [19]. The higher difference in the corrosion rate in $\mathrm{CrN} / \mathrm{AlN}$ material is characteristic of multilayer structures as a consequence of nanometric layers with low bilayer period $(\Lambda)$. The density and the interface number are also high for a uniform thorough thickness of the multilayer system; hence,
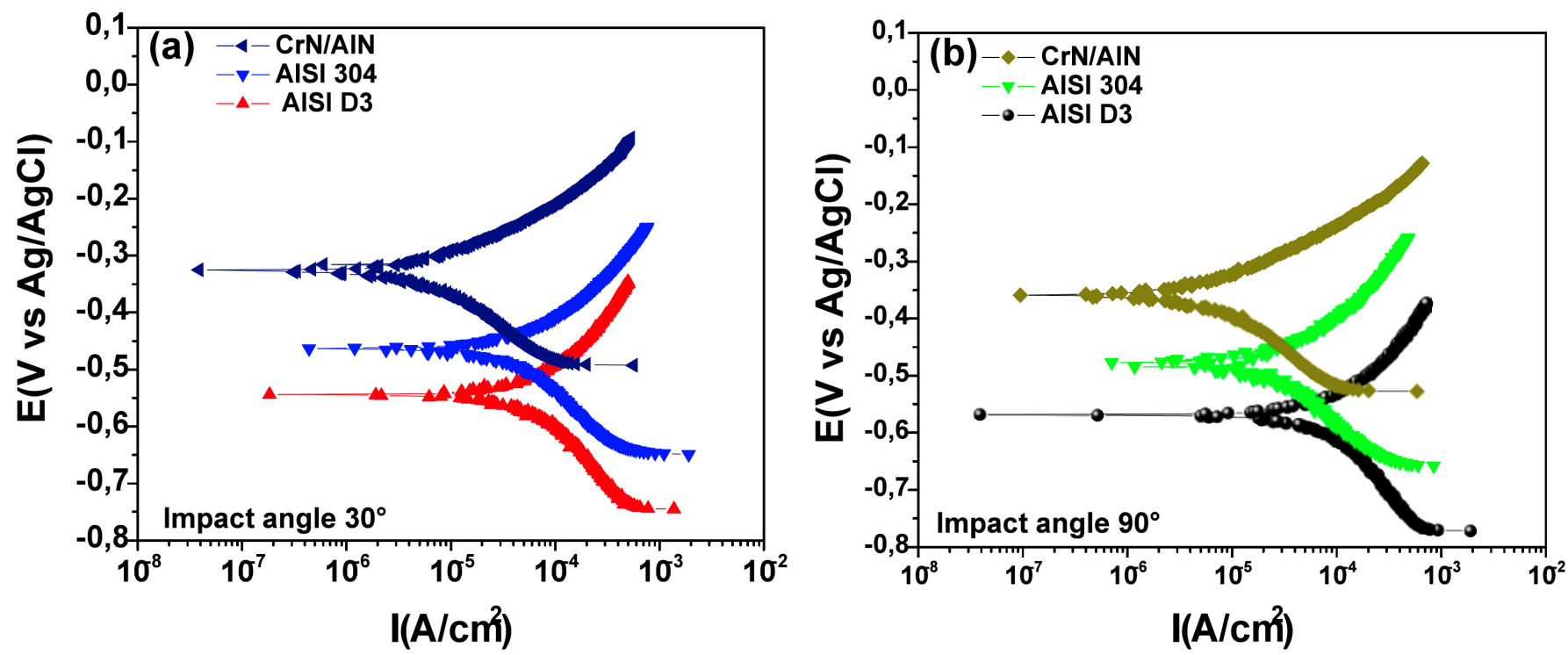

Fig. (5). Tafel curves of corrosion without erosive effect with two differents impact angles: (a) $30^{\circ}$ with lower corrosive potential (b) $90^{\circ}$ with higher corrosive.

Table 4. Corrosion Rate as Function of Different Materials for Two Impact Angles $\left(30^{\circ}\right.$ and $\left.90^{\circ}\right)$

\begin{tabular}{|c|c|c|c|}
\hline & Steel AISI D3 & Stainless Steel 304 & CrN/AIN Multilayer \\
\hline \hline (Vc)Impact angle $\left(\mathbf{3 0}^{\circ}\right)$ & $21.133(\mathrm{mpy})$ & $13.442(\mathrm{mpy})$ & $2.799(\mathrm{mpy})$ \\
\hline $\mathbf{( V c )}$ Impact angle $\left.\mathbf{( 9 0}^{\circ}\right)$ & $32.476(\mathrm{mpy})$ & $21.028(\mathrm{mpy})$ & $5.413(\mathrm{mpy})$ \\
\hline
\end{tabular}



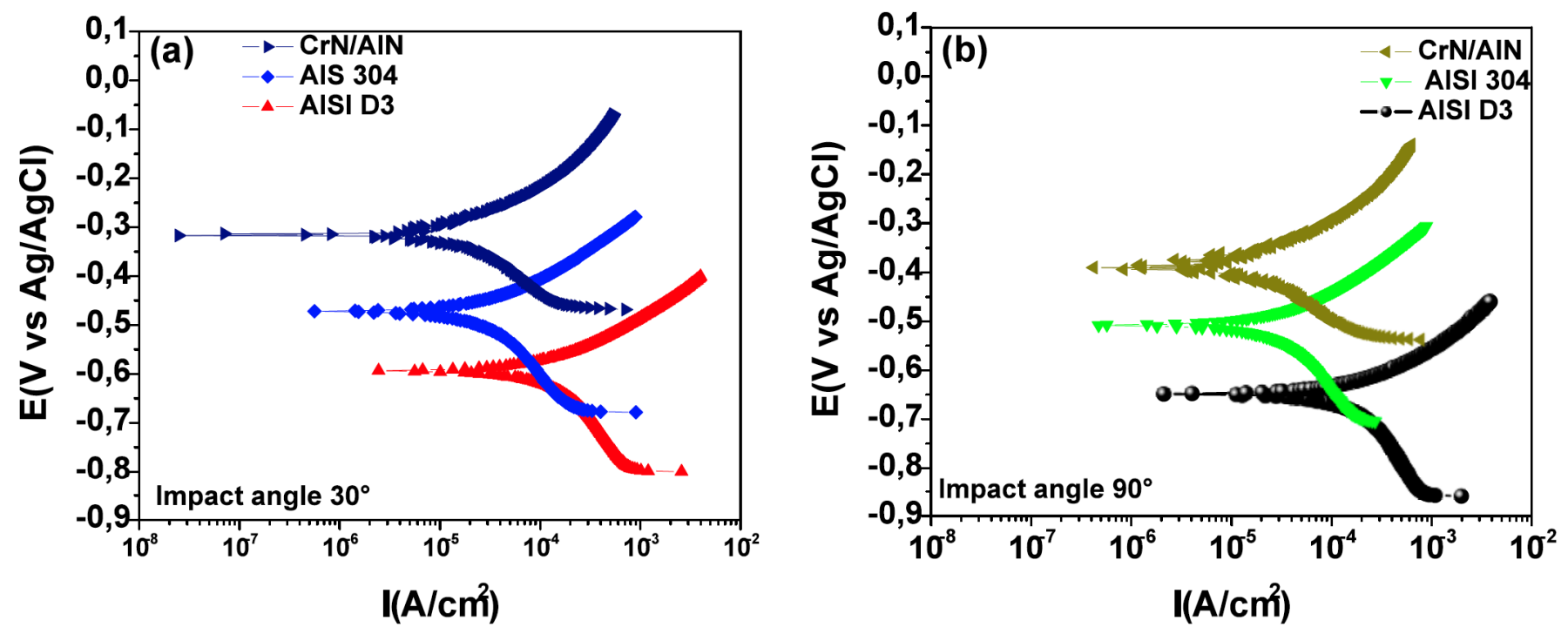

Fig. (6). Tafel curves of corrosion- erosion with two different impact angles: (a) $30^{\circ}$ and (b) $90^{\circ}$.

the number of pores is reduced. This leads to that the energy required for $\mathrm{Cl}^{-}$ions movement across the coating/substrate interface with freedom is higher; therefore, the arriving ions to the substrate are less due to the change of direction experienced by $\mathrm{Cl}^{-}$ions when these find a new interface [21].

\subsection{Corrosion-Erosion Analysis}

The corrosion behavior with erosive effect is presented in Fig. (6). Tafel polarization curves are shown in Fig. (6a, b). For two different impact angles of $30^{\circ}$ and $90^{\circ}$ a passive behavior is observed in AISI 304 stainless steel and samples coated with CrN/AlN coatings, where the coatings generate a displacement of the curves towards lower values of the current density and potentials more noble than AISI D3 steel substrate. This behavior is related to the high interface number with nanometric bilayer period $(\Lambda)$, showing in this sense better response against the wear and corrosive erosive effects [8, 22].

The Table 5 shows the values of the corrosion rate as a function of the nature of the material, in corrosion-erosion conditions to impact angles of $30^{\circ}$ and $90^{\circ}$. The curves showed a tendency towards lower values with the change in the material from AISI D3 to CrN/AIN multilayers. In the CrN/AIN case, as was showed by SEM results (Fig. 3), this type of coatings generated a great number of interfaces, which are regions that presents structural disorder and marked changes in crystallographic orientation, and can act as dispersion points preventing electrolyte spread towards the substrate which in turns cause damage in the surface. The corrosion rate values for the impact angle of $90^{\circ}$ (Table 5) show higher corrosion rate than those for an impact angle of $30^{\circ}$ in all analyzed materials. This effect is observed in samples that exhibited twice corrosion rate than steel substrates and multilayer coatings attacked with an angle of $30^{\circ}$. The reason for this behavior is attributed to the normal angles, with impact angles of $90^{\circ}$ the particles strike with great energy on the surface causing significance wear of the material. In the multilayer system it was found that the coating deposited with $\mathrm{n}=50(\Lambda=60 \mathrm{~nm})$ under an impact angle of $90^{\circ}$ provides a corrosion rate two times higher than the coating deposited with $\mathrm{n}=50(\Lambda=60 \mathrm{~nm})$ for lower impact angle of $30^{\circ}$. In this way a general trend in reduction of corrosion rate when it is observed the different materials such as AISI D3, AISI 304 and CrN/AIN multilayer coatings. Finally, in the Table $\mathbf{5}$ it is showed the reduction in the corrosion rate as function of the nature of differents material. It is seen that the highest impact angle $\left(90^{\circ}\right)$ exhibited an increase in corrosion rate for all cases when in compare with an impact angle of $30^{\circ}$.

The wear indicator such as mass loss related to corrosiveerosive systems for an exposition time of $240 \mathrm{~min}$ is showed in Table 6. In this work it was noted that the decrease in wear rate is related to passivation provided by stainless steel and multilayer coatings. This passivation mechanism is highly observed in the multilayer system for two cooperative effects. First one, multilayer coatings exhibit a higher hardness because the load is absorbed and distributed in a better way across the interfaces between different materials as $\mathrm{CrN}$ and $\mathrm{AlN}$ layers [23], gendering an increase in mechanical toughness of the multilayer coating. Second one, multilayer coatings present high interface number, which reduces the amount of arriving ions to the substrate due to the change of direction experienced by $\mathrm{Cl}$ - ions when they find a new interface. Hence, in uncoated samples (steel AISI D3), it was observed delamination in punctual zones on the steel surface because of their poor mechanical and anticorrosive properties compared with stainless steel AISI 304 or $[\mathrm{CrN} / \mathrm{AlN}]_{50}$ multilayers. The mass loss decreases for

Table 5. Corrosion Rate Under Corrosive Erosive Effect as Function of Different Materials for Two Impact Angles (30 ${ }^{\circ}$ and $\left.90^{\circ}\right)$

\begin{tabular}{|c|c|c|c|}
\hline & Steel AISI D3 & Stainless Steel 304 & CrN/AIN Multilayer \\
\hline \hline (Vc)Impact angle $\left(\mathbf{3 0}^{\circ}\right)$ & $33.40(\mathrm{mpy})$ & $23.31(\mathrm{mpy})$ & $2.79(\mathrm{mpy})$ \\
\hline$(\mathbf{V c})$ Impact angle $\left.\mathbf{( 9 0}^{\circ}\right)$ & $39.63(\mathrm{mpy})$ & $28.27(\mathrm{mpy})$ & $13.04(\mathrm{mpy})$ \\
\hline
\end{tabular}


Table 6. Mass Loss for Different Materials with Two Different Impact Angles $\left(30^{\circ}\right.$ and $\left.90^{\circ}\right)$ Under Erosive-Corrosive Effect

\begin{tabular}{|c|c|c|c|}
\hline & Steel AISI D3 & Stainless Steel 304 & CrN/AIN Multilayer \\
\hline \hline Impact angle $\left(\mathbf{3 0}^{\circ}\right)$ & $5.68 \times 10^{-3}(\mathrm{~g})$ & $3.91 \times 10^{-3}(\mathrm{~g})$ & $1.72 \times 10^{-3}(\mathrm{~g})$ \\
\hline Impact angle $\mathbf{( 9 0 ^ { \circ } )}$ & $7.96 \times 10^{-3}(\mathrm{~g})$ & $5.09 \times 10^{-3}(\mathrm{~g})$ & $3.09 \times 10^{-3}(\mathrm{~g})$ \\
\hline
\end{tabular}

both angles with the change of material nature, indicating acceptable behavior for AISI 304 stainless steel and good performance for steel AISI D3 coated with multilayer under corrosive-erosive conditions. Moreover, it was confirmed that corrosion-erosion strongly depends of the impact angle. On the other hand, the mass loss under corrosive-erosive effect is higher than that mass loss without corrosive effect or without erosive effect since the synergistic effect between corrosion and erosion have a bigger impact on decreasing the wear resistance of a material.

\section{SURFACE ANALYSIS AFTER EROSIVE-CORRO- SIVE ATTACK}

Scanning electron microscopy (SEM) micrographs are shown in Figs. $(7,8)$ for AISI D3 steel, AISI 304 stainless steel and AISI D3 substrate coated with CrN/AIN nanometric multilayer deposited with $\mathrm{n}=50(\Lambda=60 \mathrm{~nm})$ under corrosion-erosion processes for $30^{\circ}$ and $90^{\circ} \mathrm{impact}$ angles. When the impact angle is $30^{\circ}$, Fig. (7a) shows that a crack has been generated on the uncoated AISI D3 steel by wearing mechanisms, thus exhibiting an intergranular and pitting corrosion with an intense plastic deformation. The white areas reflect the surface damage caused by corrosion attack. Fig. (7b) shows a less wear damage compared to AISI D3 due to different microstructure and chemical composition. Fig. (7c) shows the surface of AISI D3 substrate coated with the CrN/AlN multilayer without fracture, which exhibits the protection afforded by multilayer coating on steel substrate.

When the impact angle is $90^{\circ}$, Fig. (8a) shows the surface of uncoated AISI D3 steel substrate evidencing a more aggressive attack than that of $30^{\circ}$ impact angles, creating thus, high corrosive wear. In Fig. (8b) is presented the surface degradation for AISI 304 stainless steel where the corrosive-erosive wear is observed with lower damage than that of AISI D3. Fig. (8c) shows a fractured surface where the coating has been delaminated due to abrasion phenomenon caused by energetic particles that impact in normal angle on the $[\mathrm{CrN} / \mathrm{AlN}]_{50}$ surface showing thus, the great aggressive effect.
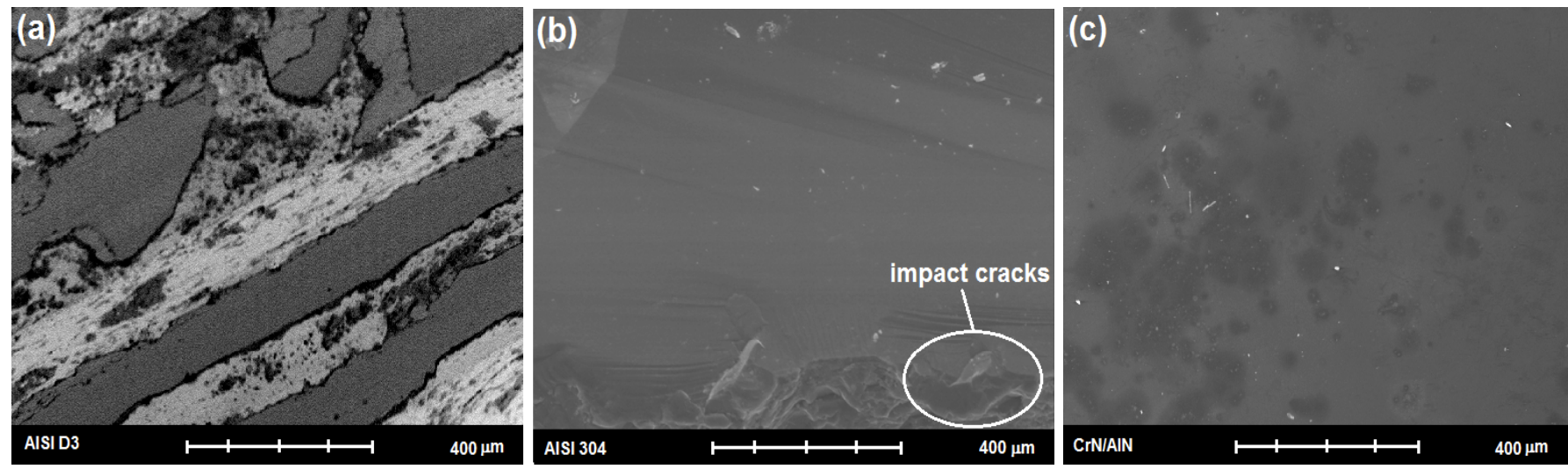

Fig. (7). SEM micrographs for samples under corrosion-erosion processes: (a) AISI D3 steel uncoated showing wear process, (b) AISI D3 stainless steel showing corrosive damage (impact cracks) and (c) steel/[CrN/AlN $]_{50}$ with impact angle of $30^{\circ}$.
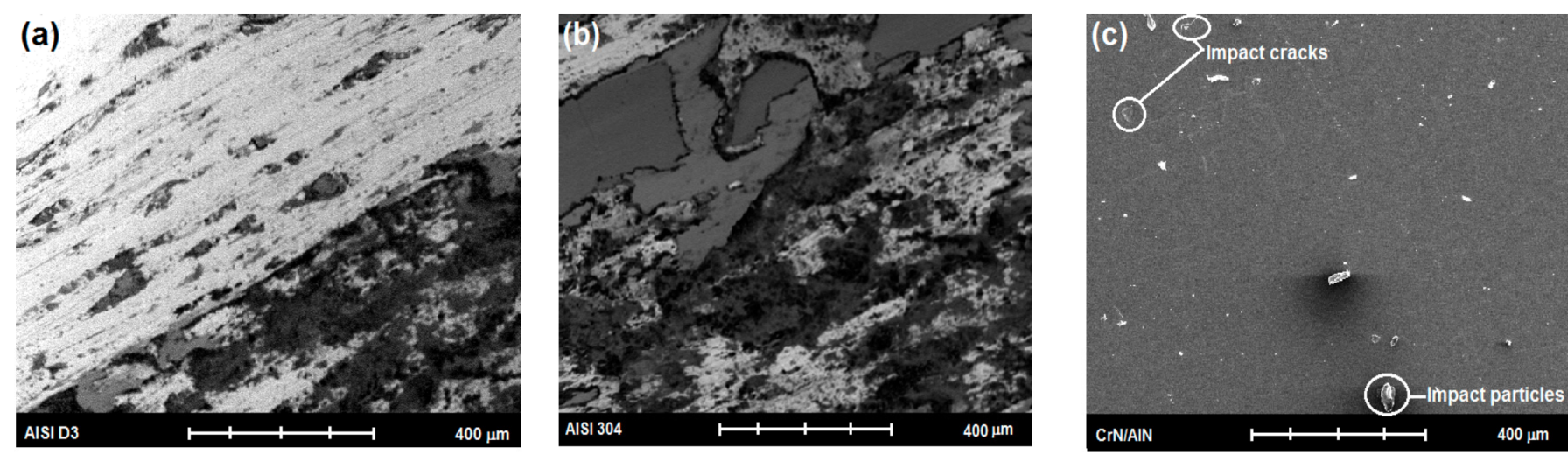

Fig. (8). SEM micrographs for samples under corrosion-erosion processes: (a) AISI D3 steel uncoated showing wear process, and corrosive damage, (b) AISI D3 stainless steel sowing wear process together with corrosive damage and (c) steel/[CrN/AlN] $]_{50}$ sowing corrosive damage (impact cracks) with impact angle of $90^{\circ}$. 


\section{CONCLUSIONS}

Corrosion-erosion mechanisms were found after carrying out polarization tests and surface examination of AISI D3 steel, AISI 304 stainless steel samples and AISI D3 coated CrN/AlN multilayers. AISI D3 steel substrates showed profuse intergranular and pitting corrosion, while AISI 304 material presented low plastic deformation due to synergistic effects.

The erosive effect and corrosive effect are lower when the differents materials are not subjected to erosive-corrosive effect. The $[\mathrm{CrN} / \mathrm{AlN}]_{50}$ multilayer coatings improves the performance (wear and corrosion resistant) for AISI D3 steel under corrosion-erosion processes, as was presented by Tafel curves for $30^{\circ}$ and $90^{\circ}$ impact angles. The material degradation under corrosive-erosive effect is higher than that corrosive effect or erosive effect due to the presence of corrosive-erosive synergism. Wear corrosion mechanisms found after corrosion-erosion tests were micro-cutting and micro-plow for an impact angle of $30^{\circ}$. Finally, generation of craters and surface cracking for impact angle of $90^{\circ}$ had the highest aggressive effect as observed by SEM micrographs.

In this work it was observed for AISI 304 stainless steel a reduction in the mass loss around 1.56 times than that AISI D3 steel. Moreover, it was found for AISI D3 steel coated with $[\mathrm{CrN} / \mathrm{AlN}]_{50}$ multilayers a reduction in the mass loss around 2.57 times than that AISI D3 steel uncoated substrates. Finally it was found for AISI D3 steel coated with $[\mathrm{CrN} / \mathrm{AlN}]_{50}$ multilayers a reduction in the mass loss around 1.64 times than AISI 304 stainless steel material for the highest impact angle of $90^{\circ}$.

\section{ACKNOWLEDGEMENT}

Declared none.

\section{CONFLICT OF INTEREST}

Declared none.

\section{REFERENCES}

[1] Annual Book of ASTM Standards 2002. Section 03, 03-02, G11993, 2002.

[2] Lopez D, Congote JP, Cano JR, Toro A, Tschiptschin AP. Effect of particle velocity and impact angle on the corrosion-erosion of AISI 304 and AISI 420 stainless steels. Wear 2005; 259: 118-24.

[3] Burstein GT, Sasaki K. Effect of impact angle on the slurry erosion-corrosion of 304L stainless steel. Wear 2000; 240: 80-94.

[4] Aiming F, Jinming L, Ziyun T. An investigation of the corrosive wear of stainless steels in aqueous slurries. Wear 1996; 193: 73-7.

[5] Toro A, Sinatora A, Tanaka DK, Tschiptschin AP. Corrosionerosion of nitrogen bearing martensitic stainless steels in seawaterquartz slurry. Wear 2001; 251: 1257-64.
[6] Neville A, Hodgkiess T, Dallas JT. A study of the erosioncorrosion behavior of engineering steel for marine pumping applications. Wear 1995; 187: 497-507.

[7] Cabrera G, Torres F, Caicedo JC, Aperador W, Amaya C, Prieto P Improvement of Electrochemical Surface Properties in Steel Substrates Using a Nanostructured CrN/AlN Multilayer Coating. JMEPEG ASM International. DOI: 10.1007/s11665-010-9798-7.

[8] Aperador W, Caicedo JC, España C, Cabrera G, Amaya C. Bilayer period effect on corrosion-erosion resistance for [TiN/AlTiN]n multilayered growth on AISI 1045 steel. J Phys Chem Solids 2010; 71: 1754-9.

[9] Caicedo JC, Yate L, Cabrera G, Aperador W, Zambrano G, Prieto P. Effect of negative bias voltage on mechanical and electrochemical nature in Ti-W-N coatings. J Mater Sci 2011; 46: 1244-52.

[10] Lopez D, Sanchez C, Toro A. Corrosion-erosion behavior of TiNcoated stainless steels in aqueous slurries. Wear 2005; 258: 684-92.

[11] Purandare YP, Stack MM, Hovsepian PEh. Velocity effects on erosion-corrosion of $\mathrm{CrN} / \mathrm{NbN}$ "superlattice" PVD coatings. Surf Coat Technol 2006; 201: 361-70.

[12] Stack MM, Purandare Y, Hovsepian P. Impact angle effects on the erosion-corrosion of superlattice $\mathrm{CrN} / \mathrm{NbN}$ PVD coatings. Surf Coat Technol 2004; 188-189: 556- 65.

[13] Suresha SJ, Math S, Jayaram V, Biswas SK. Toughening through multilayering in TiN-AlTiN films. Philos Mag 2007; 87: 2521-39.

[14] Zhao ZB, Rek ZU, Yalisove SM, Bilello JC. Nanostructured. Chromium Nitride Films with a Valley of Residual Stress. Thin Solid Films 2005; 472: 96-104.

[15] Han Z, Tian J, Lai Q, Yu X, Li G. Effect of N2 Partial Pressure on the Microstructure and Mechanical Properties of Magnetron Sputtered CrNx Films. Surf Coat Technol 2003; 162: 189-93.

[16] Barata A, Cunha L, Moura C. Characterisation of Chromium Nitride Films Produced by PVD Techniques. Thin Solid Films 2001; 398 -399: 501-6.

[17] Cabrera G, Caicedo JC, Amaya C, Yate L, Muñoz Saldaña J, Prieto P. Enhancement of mechanical and tribological properties in AISI D3 steel substrates by using a non-isostructural CrN/AlN multilayer coating. Mater Chem Phys 2011; 125: 576-86.

[18] Wang HW, Stack MM, Lyon SB, Hovsepian P, Münz W-D. The corrosion behaviour of macroparticle defects in arc bond-sputtered CrN/NbN superlattice coatings. Surf Coat Technol 2000; 126: 27987.

[19] Fenker M, Balzer M, Jehn HA, Kappl H, Lee J-J, Lee K-H, Park HS. Improvement of the corrosion resistance of hard wear resistant coatings by intermediate plasma etching or multilayered structure. Surf Coat Technol 2002; 150: 101-6.

[20] Nazarenko PV, Molyar AG, Polishchuk IE, Yachinskaya OG, Il'in AA. Structural defects and the electrochemical properties of nitride coatings. Metal Sci Heat Treatment 1990; 32(4): 305-8.

[21] Jehn HA. Structural defects and the electrochemical properties of nitride coatings. Surf Coat Technol 2000; 125: 212-7.

[22] William Grips VK, Harish Barshilia C, Ezhil Selvi V, Kalavati, Rajam KS. Electrochemical behavior of single layer CrN, TiN, TiAlN coatings and nanolayered TiAlN/CrN multilayer coatings prepared by reactive direct current magnetron sputtering. Thin Solid Films 2006; 514: 204-11.

[23] Afrasiabi A, Saremi M, Kobayashi A. A comparative study on hot corrosion resistance of three types of thermal barrier coatings: $\mathrm{YSZ}, \mathrm{YSZ}+\mathrm{Al}_{2} \mathrm{O}_{3}$ and $\mathrm{YSZ} / \mathrm{Al}_{2} \mathrm{O}_{3}$. Sci Eng A 2008; 478: 264-9. 